\title{
APRENDIZAGEM E METACOGNIC̣ÃO NO ENSINO DE METODOLOGIA CIENTíFICA
}

\author{
Maurício Abreu Pinto Peixoto* \\ Marcos Antonio Silva** \\ Cristiane Casquilha Rocha***
}

RESUMO: É necessário construir novas metodologias que auxiliem o aprendiz na percepção de seus processos de aprendizagem. Relatou-se o uso de estratégias metacognitivas para ensinar método científico a 23 estudantes de pós-graduação. Baseado na abordagem construtivista, utilizou-se técnicas de mobilização para promover o conflito cognitivo entre as crenças dos alunos sobre o pensar científico e tarefas simuladas durante um curso de metodologia científica. Diários de campo foram usados para favorecer no estudante a consciência dos seus processos de aprendizagem e como ferramenta de observação das diferenças individuais na recepção das informações e possíveis transferências. Concluiu-se que os relatos permitiram observar efeitos abrangentes no comportamento e no pensar dos estudantes.

Palavras-chave: Metacognição. Metodologia Científica. Aprendizagem.

\section{LEARNING AND METACOGNITION ON SCIENTIFIC METHODOLOGY}

ABSTRACT: There's a need of new methodologies to assist the learner in the perception of their learning processes. This paper reports the use of metacognitive strategies to teach scientific method to 23 graduate health students. Based on the constructivist approach we used techniques of mobilization to promote cognitive conflict between the beliefs of students about scientific thinking and simulated tasks for a scientific methodology course. A reflective journal was used to encourage the student awareness of their learning processes and as a tool for observation of individual differences in receiving information and possible knowledge transfers.It was concluded that the reports allowed observe widespread effects on the behavior and thinking of students.

Keywords: Metacognition. Scientific Methodology. Learning.
* Doutor em Medicina. Professor Adjunto do Núcleo de Tecnologia Educacional para Saúde (NUTES) da Universidade Federal do Rio de Janeiro (UFRJ). Líder de Pesquisa do Grupo de Estudos em Aprendizagem e Cognição (GEAC). E-mail:

geac.ufrj@gmail.com * * Pedagogo da Universidade Estadual do Rio de Janeiro (UERJ). Coordenador da disciplina de Fundamentos da Educação III dos cursos de Licenciatura em Matemática, Física e Ciências Biológicas do Consórcio da Fundação Centro de Ciências e Educação Superior a Distância do Estado do Rio de Janeiro (CEDERJ) da Universidade Estadual do Rio de Janeiro (UERJ). Mestrando do Núcleo de Tecnologia Educacional para Saúde (NUTES) da Universidade Federal do Rio de Janeiro (UFRJ). E-mail: marasih2003@yahoo.com.br ** Fonoaudióloga.

Mestranda do Núcleo de Tecnologia Educacional para a Saúde (NUTES) da Universidade Federal do Rio de Janeiro (UFRJ).

E-mail: cristianecasquilha@yahoo.com.br 


\section{INTRODUÇÃO}

A metodologia científica é concebida como metaciência que, enquanto processo e produto, ocupa-se do método científico e sua relação com o conhecimento científico. Apresenta também uma preocupação voltada para a natureza do método científico, tratando assim de assuntos epistemológicos (SALOMON, 1993). Segundo Lakatos e Marconi (1983) "não há ciência sem o emprego de métodos científicos". Há vários anos, um dos autores é docente responsável por uma disciplina de metodologia científica. O presente texto visa apresentar algumas reflexões didático-pedagógicas decorrentes da experiência com esta disciplina.

\subsection{Descrição da disciplina}

A disciplina de metodologia científica, ministrada de forma tradicional há vários anos por um dos autores a alunos de diferentes cursos de pósgraduação na área da saúde da Universidade Federal do Rio de Janeiro, distribuía seu conteúdo em três tópicos; filosofia da ciência, regras da comunicação científica e técnicas de pesquisa. O raciocínio científico apresentava-se implícito, fundamentando os tópicos citados. Nesta época, parecia-nos razoável pressupor que o domínio de tais tópicos implicasse no manejo adequado do raciocínio científico. Entretanto, segundo nossas observações, aparentemente isso não acontecia. Durante o desenvolvimento do curso, eram frequentes os casos de alunos de pós-graduação que, mesmo dominando, simultaneamente, tanto o conteúdo específico de suas áreas de conhecimento como também, pelo menos em parte, as técnicas de pesquisa, não eram capazes de integrar estes dois conhecimentos de modo a produzir um trabalho científico de qualidade.

Nas últimas décadas, diversos autores têm apontado em seus estudos a necessidade de uma mudança na forma como são apresentados e desenvolvidos os conteúdos nas diversas áreas do conhecimento. Paulo Freire (2000), Perrenoud (2001), Maturana (2002), Joan Rué (2003), Rubem Alves (2003), apontam para a necessidade da construção de uma nova metodologia centrada na tomada de consciência pelo aprendiz de seus próprios processos de aprendizagem e, ainda, nas relações estabelecidas no ambiente educativo como elementos fundamentais para o desenvolvimento da autonomia dos sujeitos. Constrói-se assim uma visão diferenciada ao identificado em algumas escolas de pensamento tradicionais que têm como meta apenas o fornecimento de informações para o aluno.

O conhecimento que o sujeito apresenta sobre seus próprios processos e produtos cognitivos é titulado como metacognição e está diretamente ligado à conscientização e o monitoramento dos sistemas cognitivos e emocionais. O primeiro autor a apresentar em seus estudos este conceito foi Flavell na década de 70. Acredita-se assim, ser possível estimular o raciocínio e a autonomia do aprendiz por meio da metacognição. 
Assim, a disciplina foi modificada visando dois objetivos centrais. Primeiro, auxiliar os alunos no desenvolvimento das habilidades necessárias para a construção do pensamento científico. Segundo, desenvolver a capacidade dos alunos de transferirem para outros espaços os conhecimentos construídos dentro de sala de aula. Sendo assim, a proposta da disciplina aqui apresentada não se limita à mera transmissão de informações. Busca auxiliar o desenvolvimento do raciocínio lógico do aprendiz e de sua autonomia, como também estimular algumas mudanças de comportamento acadêmico consideradas desejáveis em um aluno de pós-graduação em nível de mestrado.

De acordo com Falcão e Siqueira (2003), é possível perceber a existência de diversas representações do exercício do pensamento científico, mesmo em espaços de formação e produção científica. Pensar cientificamente é uma habilidade necessária a todos que ingressam no contexto de uma universidade. Para tal, na disciplina em tela, utilizou-se de técnicas de mobilização com a finalidade de promover o conflito cognitivo entre as crenças dos alunos sobre o pensar científico e as questões desenvolvidas durante o curso.

Fez-se o uso, no bojo desta disciplina, de uma metodologia alternativa baseada na abordagem construtivista. Segundo Delgado (2003) o construtivismo é uma proposta que tem como um de seus principais objetivos fazer com que o sujeito alcance sua autonomia. Possuir autonomia pressupõe uma capacidade de transformar, de tomar decisões próprias, de buscar novas soluções para os problemas enfrentados.

A disciplina estrutura-se em três momentos distintos, mas complementares. No primeiro momento, o objetivo é produzir uma quebra de expectativa na turma em relação à disciplina e ao docente, numa preparação para os eventos que se seguem. No segundo, os alunos são introduzidos a um método de raciocínio lógico. Finalmente, no terceiro momento, a proposta é sintetizar os conhecimentos e procedimentos apreendidos, além da ampliação da carga factual.

Assim, o docente inicia o curso fazendo uso de uma técnica de mobilização. No primeiro dia de aula, os alunos encontram sobre a mesa do professor dezenas de livros. O professor, então, abstém-se de uma apresentação tradicional de início de curso e submete os alunos a uma situação insólita. Afirma que deverá se ausentar em função de sua licença sabática. Cabe aos alunos, como tarefa, durante sua ausência, produzir uma monografia sobre um tema pertinente ao conteúdo do curso, fazendo uso da biblioteca do professor. Não há, inicialmente, qualquer orientação extra. Os livros são intencionalmente empilhados de forma aleatória sobre a mesa, abrangendo múltiplos assuntos, inclusive alguns estranhos ao tema do curso.

De imediato é possível perceber que os alunos mostram-se inibidos com a tarefa. O professor, que no início, adota uma postura passiva, progressivamente estimula os alunos a acessarem os livros, procurando auxiliá-los a identificar seus conteúdos, organizá-los em categorias, determinar temas perti- 
nentes ao curso. Progressivamente, facilitado pelo professor, os alunos dão-se conta do objetivo inicial do docente: auxiliar os alunos no desenvolvimento de habilidades necessárias para a construção do pensamento científico. Neste primeiro momento, são enfatizados os processos de pensamento que podem dificultar ou facilitar a execução das tarefas, conforme sua utilização adequada ou não. nfase semelhante se faz também sobre a consciência do aluno em relação ao seu próprio processo de pensamento. Evidencia-se, aqui, uma preocupação do docente em favorecer o conhecimento metacognitivo, o que irá se estender por todo o curso.

No segundo dia do curso, inicia-se o segundo momento do curso. A turma é desafiada a resolver um problema científico hipotético. Utiliza-se um vídeo comercial de ficção científica que tem como função apresentar o problema. A obra é completa, no sentido que o apresenta, desenvolve e mostra a solução. A exibição é realizada em partes, ao longo de várias aulas, respeitando tanto a lógica do filme como a do planejamento pedagógico. O objetivo aqui é apresentar cada uma das partes, numa sequência em que diversos problemas científicos são apresentados, cabendo aos alunos propor soluções para estes, e simultaneamente observar a solução apresentada no vídeo resposta para a questão anterior.

Por fim, no terceiro momento, o docente trabalha de forma semelhante à etapa anterior, porém aumentando a complexidade. Agora, a turma é desafiada a interpretar a obra de Latour e Woolgar intitulada "Vida de Laboratório". Este trabalho propõe uma descrição geral do que seria o processo de construção do fato científico, a partir da descrição e análise de eventos ocorridos no laboratório de neuroendocrinologia do Instituto Salk.

A avaliação da disciplina é realizada a partir de dois instrumentos. O primeiro é a apresentação de um diário de campo construído ao longo do curso pelo aprendiz. O segundo é um artigo onde o aluno-autor testa a hipótese de que o curso foi capaz de modificar seu paradigma sobre ciência. Enfatiza-se reiteradamente que a avaliação se dará sobre a forma de argumentar e não sobre se a hipótese é rejeitada ou aceita. Tanto a construção do diário de campo, quanto a produção do artigo pelo aluno podem ser considerados exemplos de avaliações processuais ou de desempenho, cuja finalidade é a de conhecer e analisar a atuação e o desenvolvimento do aluno ao longo do curso. Esse tipo de avaliação tem como base a concepção de que os participantes de qualquer curso em geral possuem diferentes motivações, estilos, ritmos e experiências prévias com o objeto de estudo, o que pode resultar em percursos e níveis de atuação diversificada nas atividades propostas (STRUCHINER; GIANNELLA, 2001).

O diário de campo foi utilizado com dupla função. Primeiro para favorecer no estudante a consciência dos seus processos de aprendizagem. Depois, pelos pesquisadores como ferramenta de observação. Desejava-se identificar possíveis mudanças na forma como os alunos recebiam as informações apresentadas e suas possíveis transferências para outros espaços. 
Usado desta forma, permite observar a capacidade de raciocínio do aluno e as relações entre o conteúdo do curso e as mudanças pessoais e acadêmicas que a partir dele são relatadas. Estimula a auto-reflexão e a verbalização de acontecimentos, tais como sensações e sentimentos diante das dificuldades, transferências e/ou associações dos assuntos tratados na disciplina com outros espaços e tempos educacionais como no exemplo abaixo':

"A cada diário de campo escrito, alguma mudança seria descrita associada às técnicas sugeridas nas aulas. Desta forma, as ideias juntamente com os fatos ficavam organizadas no pensamento, permitindo a condução por uma linha de raciocínio que chegaria a um objetivo, sem se distanciar da ideia principal.” (A.G.)

O uso de diários de campo na educação já está bem estabelecido (ZABALZA, 1994). Têm sido utilizados principalmente para coletar dados (CRUZ; FERREIRA, 2005, p. 163-180; GOMES, 2002; GÜNTHER; NETO, 2000, p. 78-84; MONTEIRO et al., 2004; PEREIRA, 2002; SORIANO; WINTERSTEIN, 2004, p. 315-332). Já na área da saúde, a literatura internacional relata o uso de diários de campo para a coleta de dados principalmente na área da enfermagem (RICHARDSON, 1994, p. 782-791; STOLLER, 1993); e na área da psicologia para interpretar processos cognitivos (NORMAN; PARKER, 1996, p. 301-314; WILLIS; BERCINI, 2006, p. 251-267) e ainda, na coleta de dados do comportamento de pessoas idosas (RAKOWSKI et al., 1988; STOLLER et al., 1993, p. 58-81). No entanto, autores nacionais têm feito poucos relatos, sendo mais utilizado na área de enfermagem (MOURA, 2003; RESTA; BUDÓ, 2004, p. 53-60; RIBEIRO; MUNARI, 1998, p. 147-164; SILVA; LOPES, 2006, p. 240-250; TRONCHIN et al., 2006; TRONCHIN; TSUNECHIRO, 2006; ZAGO, 1990) e no campo da psicologia (ALVAREZ, 1999; OLIVIERA; BASTOS, 2000) ambos com o objetivo de coletar dados.

Cabe ressaltar que o enfoque deste artigo centra-se no diário de campo como ferramenta didática, sendo que seu uso como técnica de pesquisa está situado em um segundo plano. Torna-se importante, assim, ressaltar a diferença entre diário de campo científico e didático. $\mathrm{O}$ científico registra os eventos que acontecem e o didático utiliza o registro como ferramenta de aprendizagem. Neste estudo utilizamos o diário de campo didático que permite ao aluno a construção de uma nova forma de visualização de seus próprios processos.

A crescente importância dos documentos pessoais - referentes às histórias de vida de sujeitos em seus respectivos contextos - para uma análise qualitativa dos contextos sociais numa visão mais ampla, pode ser identificada em diversos estudos, a partir da década de 40 (ZABALZA, 1994). Especificamente, em relação aos contextos de investigação educacional estes estudos são menos abundantes e tem seu início datado a partir da segunda metade da década de 70. Na área de educação muitos professores já utilizam esta ferramenta, embora muitas vezes com outros nomes tais como agenda temática, portifólio, diário de classe. Portifólios são coleções de produtos acabados. É muito comum 
em alguns ambientes educacionais sua apresentação ao final do ano letivo como um elemento de avaliação do trabalho tanto do professor como do aluno. Já o diário de campo tem como objetivo registrar os acontecimentos do cotidiano como uma forma de compreender como se desenvolveu, ao longo de um determinado período, um aluno ou grupos de alunos. A diferença que se estabelece aqui é que muitas vezes no exercício de seu ofício, o professor costuma se prender mais aos fatos ocorridos do que à sua análise sobre os mesmos.

\subsection{Referencial teórico da disciplina}

Do ponto de vista pedagógico, a disciplina em tela foi planejada e implantada tendo como base alguns estudos no campo das teorias cognitivas. Um deles foi a teoria da equilibração proposta por Piaget (1978), ao promover dissonância entre conceitos prévios do aluno e aqueles apresentados e vivenciados em variadas situações do curso. Segundo trabalhos de Robert e Sternber (2000), Campos (2001), Delgado (2003), Matui (2005), podemos afirmar que, em essência, um sistema de equilíbrio é aquele que possui algum tipo de estabilidade, com respeito às diversas forças que atuam sobre ele ou em seu interior.

Outra contribuição importante foram os estudos do psicólogo russo L. S. Vygotsky (2003a, 2003b). Duas foram suas principais contribuições para esta disciplina. Seus estudos sobre o processo de internalização do conhecimento como algo proveniente do contexto social, demonstrando o papel essencial das relações sociais para o desenvolvimento da aprendizagem. E a importância dada pelo autor ao conceito de zona de desenvolvimento proximal dentro do processo de ensino-aprendizagem. Embora esta abordagem seja diferente da apresentada por Piaget que enfatiza a maturação das estruturas cognitivas, nosso interesse aqui é o de unir os dois teóricos, no sentido de compreender que, tanto a maturação das estruturas cognitivas ${ }^{2}$ quanto as interações desenvolvidas pelos indivíduos são responsáveis pela aprendizagem.

E por fim, apresentamos o conceito de metacognição como uma importante ferramenta no desenvolvimento da autonomia do aluno. Neste sentido, o docente responsável utilizou-a frequentemente como tecnologia educacional simbólica (PEIXOTO et al., 2007, p. 67-80), visando favorecer o desenvolvimento do raciocínio científico da classe.

Os diferentes tipos de métodos de ensino têm forte influência na maneira pela qual este equilíbrio é modulado. Farnham-Dyggory (1994, p. 463477) apresenta três paradigmas instrucionais; o comportamental, o noviciado e o evolutivo, os quais definem a maneira pela qual um noviço pode ser diferenciado do especialista. No primeiro a diferença é predominantemente quantitativa. O especialista sabe mais, faz mais rápido, apresenta-se melhor que o noviço. O aprendizado se faz de maneira incremental, cabendo ao ensino o fornecimento regular e continuado de novos conhecimentos. No noviciado o que existe é a aculturação; o noviço progressivamente assimila a cultura do mestre. Ao final do processo, mestre e aprendiz fazem parte do mesmo mundo afetivo e cognitivo. 
Já no evolutivo, a diferença se faz pelas teorias explicativas da realidade que um e outro possuem. A diferença é qualitativa, possuindo o especialista modelos mais complexos, abstratos e sofisticados que o noviço. Aqui o aprendizado se faz por perturbação, onde os modelos do noviço são continuamente questionados e desconstruídos. Foi este o paradigma instrucional utilizado para orientar a disciplina aqui descrita.

\section{MATERIAIS E MÉTODOS}

A turma era formada por profissionais da área da saúde, tais como médicos e fonoaudiólogos, além de alguns poucos da área de educação.

Foram analisados 23 diários de campo produzidos pelos alunos do Curso de Metodologia Científica do NUTES/UFRJ no ano de 2001. Os diários apresentados foram confeccionados tendo como eixo central as vivências dos alunos ao longo do curso. Para cada duas aulas os alunos apresentavam um diário de campo, que ao final do processo possibilitaria observar em que medida o curso, como um todo, auxiliou no desenvolvimento cognitivo do aprendiz. Quanto ao formato dos textos nenhuma orientação mais rígida foi apresentada aos alunos, deixando-os mais livres para fazer suas anotações. Os textos foram estudados pela análise de discurso (GILL, 2002, p.244-270). Compreendendo a realidade humana como um conjunto de práticas discursivas que interagem entre si, nossa tarefa, neste instante, foi identificar que categorias empíricas afloraram a partir do discurso dos alunos. Inicialmente foi realizada uma leitura superficial tentando identificar o estilo de escrita dos alunos. Depois foi realizada uma leitura mais profunda tentando identificar elementos que pudessem ser utilizados como categorias para a sistematização dos dados.

\section{RESULTADOS E DISCUSSÃO}

\subsection{Análise dos relatos}

Observamos, ao longo de nossa análise, que os alunos utilizaram uma linguagem descritiva dos acontecimentos, seguido por um formato mais narrativo e com menor prevalência o dissertativo. Estes relatos foram escritos, em sua maioria, na primeira pessoa. Percebemos que a escrita é o reflexo de uma conduta habitual do sujeito em relação à forma como processa as informações, transformando-as em conhecimento. Atua como uma espécie de medidor da qualidade das interações desenvolvidas durante as atividades, permitindo que o docente possa reorganizar-se de uma forma mais eficiente.

Todos os eventos descritos nos diários de campo podiam ser classificados em dois grandes grupos: eventos de sala de aula e eventos externos. 
"O curso de metodologia científica foi dividido em duas partes, utilizando como método na primeira parte o filme "O enigma de Andrômeda" e na segunda parte o livro "A vida de laboratório."” (A.G.D.)

"Quantas vezes, na nossa prática de consultório, o quadro clínico do paciente se resolve sem se saber a real causa daquela patologia. Pode-se sanar uma cefaléia com analgésico sem se saber a causa." (A.G.D.)

Estas duas categorias nos permitiram identificar: a) Como o aluno percebeu a divisão estrutural da disciplina; b) Momentos específicos, exemplos dados pelo professor ou outro colega que foram marcantes para seu aprendizado.

\subsection{Sobre as expectativas dos alunos}

Observamos que uma parte dos alunos não apresentava qualquer expectativa em relação à disciplina. Outra parcela da turma declarou que esperava receber regras, conceitos ou um grande número de informações. Um número menor ainda declarou que esperava que suas habilidades fossem testadas durante o desenvolvimento da disciplina. Grande parte dos alunos entrou no curso tendo um discurso internalizado sobre como deveria ser uma aula inaugural baseada em um modelo de ensino tradicional, onde o professor se apresenta, fala da sua experiência, apresenta um cronograma, etc. Quando o docente rompe com o modelo tradicional, apresentando uma dinâmica desconhecida ao aluno, também é rompido o equilíbrio cognitivo do aprendiz. Vejamos alguns relatos:

"O impacto sentido na $1^{a}$ aula foi forte. Olhar toda aquela pilha de livros desconhecidos, de variados assuntos, com a maioria não sendo do meu dia-a-dia, foi angustiante. Quando o Sr. falou da tarefa que precisávamos realizar, escolhendo os livros que julgássemos melhor, para um trabalho de metodologia científica, em que aparentemente o Sr. não estaria presente para nos orientar de perto, fiquei um tanto quanto admirado e perplexo.” (M.C.D.)

"Imaginava receber formalmente definições e talvez regras sobre "métodos". Lendo os artigos médicos, e mesmo formulando alguns, me vejo confusa com a terminologia utilizada, e achava que iria então, por meio das aulas, me familiarizar com esses termos." (C.C.R.)

"Minha expectativa inicial em relação ao curso de Metodologia Científica era de que, mais uma vez, receberia um grande número de informações acompanhadas de um igual número de normas de como utilizá-las da maneira correta." (J.V.G.)

Na primeira fala podemos observar como o aprendiz se vê diante de uma situação nova e nas falas seguintes, quais são suas expectativas em relação à disciplina. 


\subsection{Reflexão e introspecção}

Voltando para a análise do conteúdo presente nos diários de campo podemos notar na escrita dos alunos dois tipos de movimento. Um deles foi o de reflexão mais voltado para a descrição da importância dos eventos desenvolvidos ao longo do curso para a formação do profissional, do cientista, pesquisador como no caso abaixo:

"Individualmente, entendi que a capacidade de pensar existe e necessita ser utilizada por meio de um grau elevado de concentração. Tanto na área pessoal quanto profissional e emocional, a aplicação do raciocínio lógico possibilita alcançar estratégias direcionadas para solução de todos os tipos de problemas." (A.G.O.)

Outro movimento foi o de introspecção referente à forma como os eventos decorrentes da dinâmica do curso auxiliaram no desenvolvimento de uma mudança efetiva de comportamento como no caso abaixo:

\footnotetext{
"As aulas têm me provocado um comportamento muito rigoroso nas leituras que venho fazendo para a formulação do anteprojeto. Pego-me lendo e relendo inúmeras vezes o mesmo texto para confirmar se o que estou considerando é realmente um dado ou reflexão minha, para que eu também não deforme os dados. Muitas vezes também percebo que é preciso atentar para o vocabulário utilizado, pois palavras aparentemente semelhantes podem estar referidas a conceitos diferentes, o que pode me levar a falsas conclusões. É preciso clareza na escolha das palavras e conceitos que eu vou utilizar." (K.G.)
}

Neste caso, observamos como esta introspecção aumenta o grau de consciência sobre o seu próprio processo cognitivo. Dito de outra forma, como pelo menos neste caso, a disciplina contribuiu para o desenvolvimento cognitivo do aluno. Aqui podemos observar, no mínimo, duas características metacognitivas. Uma delas, o aumento da consciência sobre a cognição - a metacognição propriamente dita. A outra, o estímulo a um maior rigor no pensamento científico, que aqui não se faz de forma genérica. A consciência recém-adquirida permite ao aluno focar de forma mais precisa a sua crítica. A metacognição, já em desenvolvimento, permite-lhe identificar mais claramente os pontos críticos da formulação do seu anteprojeto de pesquisa; neste caso a ilusão da transparência ${ }^{3}$ e precisão no uso dos conceitos. E assim é esperável que sob esta visão mais rigorosa, o resultado final seja mais adequado.

\subsection{Conflito}

Um dos elementos que mais nos chamou atenção ao lermos os diários de campo dos alunos foi a descoberta de um campo de tensão entre os conhecimentos prévios que estes trouxeram para a disciplina e os conhecimentos apresentados pelo docente durante a dinâmica do curso. Podemos caracterizar o conflito como um momento onde as certezas do aluno são destituídas de um valor de verdade, causando desequilíbrio na forma como o indivíduo constrói sua forma de explicar a realidade. 
"Espero sinceramente que o curso resista às diversas dificuldades que têm surgido, pois me sinto uma criança que começa a querer dar os primeiros passos, mas ainda não está pronta para largar a mão do adulto protetor. Espero que ao final do curso, mesmo que ainda não saiba correr, possa, ao menos, não temer tanto os tombos.” (R.R.M.)

Durante a disciplina foram observados três momentos em que este tipo de situação foi mais frequentemente identificado. O primeiro surgiu logo no primeiro encontro, quando os alunos esperavam um tipo de aula, tendo como base suas próprias concepções de como deveria ser uma aula inaugural "tradicional". Este primeiro momento de conflito tem como elemento deflagrador a quebra de um tipo de expectativa do aluno.

“[...] que principalmente nós médicos estamos acostumados com pensamento concreto e protocolos a serem seguidos e, que quando somos estimulados a pensar sobre como pensar e, porque (ao) pensar normalmente nos sentimos mal.” (L.A.C.)

"A primeira impressão que tive, nos primeiros momentos da primeira aula foi de que não gostaria do curso. Estava sendo colocada à prova e não gosto disso." (M.O.)

O segundo momento foi identificado a partir da exibição do filme. Aqui o elemento principal, foi a metodologia utilizada para a exibição e discussão do vídeo, realizada em partes que eram postas em debate e que se completavam a cada exibição posterior.

\begin{abstract}
"O que tem a ver metodologia científica com minha maneira de perceber fatos até mesmo corriqueiros do meu cotidiano? Ou na forma de "olhar", assistir um filme? O que está mudando é a perspectiva desse olhar, é o tornar-se mais consciente do que já se realiza ou surpreender-se com o novo, com o que antes não se podia conceber, pensar." (J.A.C.)

"Concordo que todas as ferramentas para elaborar o projeto estão no filme e não são tão impossíveis assim de serem extraídas com a ajuda da observação e do pensamento. Para a tese, isso tudo está claro e perfeito. Mas para a vida, já pensou que coisa mais cansativa? E neurótica? Não gostei muito do exemplo da maternidade. Até entendo o que se quis dizer, mas é muito diferente uma coisa prática e palpável da abstração do pensamento. Eu quero pensar, não estou resistindo. Pelo menos eu acho. Mas é que cansa muito!.” (C.C.D.)
\end{abstract}

O terceiro e último grande momento é identificado a partir da discussão do livro "Vida de Laboratório", onde numa visão preliminar a linguagem do autor parece o elemento deflagrador de conflito. Nos relatos dos alunos é muito comum perceber que nestes momentos, sentimentos como frustração, medo, desorientação, angústia, são predominantes.

"A leitura do livro proposto é tão complexa que acho que chegarei ao fim dele conseguindo apenas perceber (ao longe) que existe um paralelo entre o tipo de atividade desenvolvida lá pelo filósofo e a que nós estamos executando em sala de aula. Certo dia destes, um colega de turma citou que ao ler o referido livro havia percebido melhor o caminho proposto pelo professor para nos ensinar Metodologia Científica." (M.C.) 
"Continuo a árdua tarefa desta leitura com a esperança de que em algum momento eu venha a ter uma melhor compreensão de tudo isto.” (A.P.S.B.)

Perceber estes momentos de fragilidade e modular a ampliação da carga de complexidade nos desequilíbrios cognitivos ao longo do curso é essencial tanto para o desenvolvimento da prática pedagógica quanto para a construção da autonomia do aprendiz. O conflito entre as expectativas e conhecimentos prévios dos alunos e os desenvolvidos pelo docente apresenta-se como um elemento central no processo de ensino-aprendizagem. Identificá-lo nos permite ver as dificuldades que o aluno enfrenta em relação aos temas tratados. E permite, ainda, ao docente planejar uma ação mais eficaz.

Compreendemos o conflito como um espaço de construção de conhecimento, onde o que conta é a disponibilidade de ambas as partes no estabelecimento de um vínculo facilitador da aprendizagem. Em relação ao aluno, essa percepção possibilita que o mesmo centre esforços em determinado aspecto que considere mais complexo ou que, simplesmente, não esteja claro.

\begin{abstract}
"Considerei, no íntimo, que não mudaria em nada. As discussões não são tão estranhas ao meu conhecimento. Já havia lido sobre metodologia da pesquisa. Porém, me espanta achar que três meses depois não mudaria em nada. De hoje para amanhã, tudo muda. Como posso achar que não mudaria nada. Porque sou resistente? Uma das perguntas que fiz inicialmente foi: "para mudar tenho de saber o que penso hoje" e o professor respondeu que para isto é que servem os diários de campo." (N.N.C.)
\end{abstract}

\title{
3.5. Ampliando Horizontes
}

O uso metacognitivo do diário de campo como uma ferramenta de monitoramento e gerência da aprendizagem permite ao aluno ampliar sua capacidade de exercício, planejamento e análise do pensamento científico, intensificando a capacidade de comunicação e argumentação entre os pares.

"O exercício do raciocínio foi crescendo a cada dia juntamente com a progressão das aulas. Os diários de campo, escritos a cada quinze dias, funcionaram como uma coleta de dados que foram fundamentais para direcionar as mudanças na forma de pensar. A cada aula, um fato novo seria incluído no próximo diário de campo, organizando o pensamento e as ideias." (A.G.O.)

"Pensar em metodologia pode significar pensar ou repensar como ocorreu o próprio processo de aprendizagem e ficar perplexo ao constatar o quanto ela está presente em nossas ações. Ao tomar consciência deste aspecto é possível perceber como se dá o próprio processo de aprendizagem e criação.” (J.A.C.)

"Para o ensino, um novo paradigma é proposto; nele o saber é construído interativamente e o aluno deixa de ser apenas alguém que recebe o saber já elaborado e transmitido pelo mestre. Não se trata de proposta anarquista de desaparecimento da autoridade e da figura do professor, mas da sua transformação.” (J.R.) 


\subsection{Sobre o conceito de aprendizagem}

$\mathrm{Na}$ história da Psicologia diversas correntes preocuparam-se com o tema da aprendizagem, a partir de diferentes aspectos (HILL, 1981; PENNA, 2001; POZO, 2002). Não é nosso objetivo neste estudo discorrer sobre elas. Aqui apenas tentamos refletir sobre a aprendizagem como um processo gerador de mudança de comportamento, a partir do desenvolvimento das estruturas cognitivas, aproximando-se por um lado da teoria da equilibração piagetiana e sendo influenciada pelas interações entre sujeitos, e dos sujeitos com o meio, sempre mediadas pelos signos numa referência às teorias de Vygotsky.

Tendo como base estas teorias juntamente com os relatos dos alunos, é possível pensarmos na aprendizagem como um processo de reestruturação dividido em três estágios complementares, cada qual sendo dominado por um tipo de resposta: sensorial, emocional ou racional. O estágio sensorial é identificado por uma sensação inicial de admiração, inquietação, espanto ou simplesmente quebra de expectativa diante de um novo código que nos é apresentado. É um tipo mais primário de conflito cognitivo que se estabelece entre o conhecimento prévio do aluno e a forma como o docente gerencia os eventos no cotidiano escolar.

\footnotetext{
"Após ele sair da sala, as pessoas ainda estavam espantadas e começaram a olhar umas para as outras até que alguém disse: "Acho que ele quer que a gente vá ver os livros"! Todos se levantaram, foram até a mesa e começaram a ver os livros, que eram os mais diversos." (F.A.S.)
}

No segundo estágio, denominado de estágio emocional, sentimentos como alegria, medo, revolta e angústia diante de uma tarefa que devemos concluir são predominantes. Expectativas foram quebradas. Essa quebra gera diversas atitudes motivadas não mais por sensações estimuladas pelo docente, mas pelos sentimentos de angústia, medo, experimentado a partir destes estímulos. Neste estágio, é muito comum pensarmos numa tarefa como algo do qual não somos capazes de concluir, ou pelo menos concluir como gostaríamos. É o estágio, onde começamos a dimensionar a desconstrução de nossas crenças e verdades.

\footnotetext{
"Nestas primeiras aulas de MC, me deparei com a insegurança, mais compatível com a realidade, de que não existem verdades absolutas (ou se existem são poucas...), nem tampouco as ideias e reflexões sobre um assunto podem ser limitadas em um simples programa." (R.R.M.)
}

E por fim, o estágio racional. Aqui, o aprendiz manifesta uma outra postura em relação à produção do conhecimento. Nem o código, tampouco a desconstrução de seus conhecimentos prévios é novidade. Sua busca agora é por ordem, organicidade na tentativa de equilibrar suas estruturas cognitivas e a forma como reconhece a realidade. 
"Enfim, passado o susto, tenho a dizer que nada tenho a contestar contra este tipo de apresentação de aula. Acredito que é uma maneira diferente e muito válida de chamar a atenção dos alunos para o assunto: como deveríamos começar a pensar, a organizar nosso pensamento, nossos conceitos sobre ciência, natureza, metodologia científica, projetos de pesquisa, pesquisador, etc.” (M.O.)

"Por sorte o conteúdo de nossas aulas não está servindo apenas na hora de ler artigos para a tese ou para escrever melhor. Tenho usado muito aquela frase "a inteligência precede a ação (ou alguma coisa parecida )" em minha vida pessoal. Planejo melhor tudo que faço e, por coincidência ou não, as coisas tem dado mais certo." (L.L.R.)

Durante o curso percebemos a ocorrência destes três estágios. $\mathrm{Na}$ aula inaugural houve predominância do estágio sensorial. Os alunos tinham uma concepção prévia do que seja uma aula inaugural tradicional. E o que lhes é apresentado rompe algumas de suas estruturas. Sobre o vídeo, observamos que o conflito centra-se na dinâmica de apresentação e debate. Como alunos, fomos acostumados a ver uma obra inteiramente, para depois discuti-la. E, a proposta de passá-lo em partes, debatidas a cada aula, soa, distante do que estes alunos estão acostumados. Sobre o livro, o principal elemento de conflito é a linguagem na qual o tema é apresentado. Diferente de uma linguagem mais habitual nas ciências da saúde, o autor apresenta uma linguagem mais característica das ciências humanas.

Os aprendizes, depois de vivenciarem um momento de angústia, onde seus conhecimentos e comportamentos passaram por um processo de desconstrução, percebem que o ato de registrar os passos que foram dados ao longo da disciplina permitiu a reformulação dos modos de produzir conhecimento, seja ele científico ou não.

"Percebo que para mudar minha forma de pensar, primeiro tenho de analisar como penso ou ainda que, a mudança ocorre tendo por base meu referencial” (N.N.C.)

Este é um outro momento do processo de ensino-aprendizagem. Estamos em um momento onde o conhecimento passa por um processo de aprofundamento sendo passível de transferência a partir das múltiplas relações estabelecidas pelos sujeitos em seus contextos. Neste contexto, compreendemos que o professor encontra-se não na posição tradicional de "sujeito que ensina", mas na posição de "sujeito facilitador do aprendizado" compreendido, neste caso, como uma mudança de comportamento em relação à produção de conhecimento.

\section{CONCLUSÃO}

Refletir sobre esta experiência nos permitiu identificar uma série de benefícios decorrentes do uso combinado de estratégias metacognitivas, técnicas de mobilização e diários de campo, sob um viés construtivista. Percebemos ainda 
limitações importantes nestes procedimentos didáticos. Por um lado são técnicas pouco habituais que exigem do docente aprendizado adequado e por vezes demorado. Trata-se de aprendizado que além dos aspectos meramente técnicos, envolve certo grau de transformação pessoal. Ainda mais, foi projetada para uma disciplina que trabalha na perspectiva de ênfase no desenvolvimento de processos de pensamento. Sendo assim, os benefícios para outro tipo de conteúdo são desconhecidos. Desta forma seu uso por outros docentes tem limitações. Finalmente, demanda do docente esforço adicional ao inerente ao ministério de qualquer disciplina, tanto no que se refere à condução das aulas em si, com também ao gerenciamento e avaliação dos diários de campo e artigo final.

Por outro lado, observamos que, por meio do uso desta forma alternativa de ensinar, há uma possibilidade de uma compreensão mais ampla do desenvolvimento do aprendiz no curso e, ainda, a explicitação do paradigma evolutivo presente na disciplina. Nos relatos dos alunos, viu-se com frequência o afloramento do processo de perturbação dos seus modelos explicativos, assim como sua progressiva transformação.

Do ponto de vista do aluno, o uso do diário de campo também permitiu que o mesmo ampliasse suas percepções iniciais de determinados conceitos. Identificamos ampliação da capacidade de exercício, planejamento e análise do pensamento científico, intensificando a capacidade de comunicação e argumentação entre os pares. Percebemos ainda, a existência do conflito cognitivo, algumas de suas características e consequências para aprendizagem. Assim também, o curso relatado foi capaz de gerar mobilização na turma, de maneira integrada, dos aspectos físicos, cognitivos e afetivos, gerando reações diversas nos participantes. Por fim, compreendemos que a metodologia desenvolvida possibilitou a transferência diversificada, dos temas vivenciados no interior $\mathrm{da}$ sala de aula para outros espaços e tempos educativos.

Concluindo, o presente texto não advoga qualquer tipo de superioridade desta forma alternativa de ensinar sobre qualquer outra. Entendemos que ela, respeitadas suas limitações, provê benefícios significativos quando o objetivo é promover mudanças nos processos do pensamento. Neste enquadre então, acreditamos que esta forma de ensino é uma possibilidade a disposição de docentes sintonizados com seus pressupostos. 


\section{NOTAS}

${ }^{1}$ Todas as iniciais presentes nas diversas citações ao longo deste trabalho são fictícias, para evitar a identificação dos participantes do curso.

${ }^{2}$ Ressalte-se que, muito embora o aluno seja adulto, e portanto já tendo atingido o estágio de operações formais, nem sempre o seu comportamento se mostra compatível com este, no que tange ao raciocínio científico (por conta da decalagem).

${ }^{3}$ Processo mental por meio do qual o pesquisador projeta nos dados características estranhas a eles, oriundas predominantemente de seus próprios preconceitos e vícios de raciocínio. (Bourdieu, 1983, p.54).

\section{REFERÊNCIAS BIBLIOGRÁFICAS}

ALVAREZ, A. M. S. A residência e o morar na rua: estudo com moradores de rua - criança e adultos - na cidade de São Paulo. São Paulo; s.n; 1999. 198p.

ALVES, Rubem. Entre a ciência e a sapiência: o dilema da educação. Campinas: Papirus, 2003.

BOURDIEU, P. Sociologia. São Paulo: Ática, 1983.

CARVALHO, R. O., SÁ, Selma P. C. Ensino de enfermagem fundamental: aplicação do paradigma metacognitivista em cursos de pós-graduação. Rio de Janeiro: 2003.

CRUZ, G. C.; FERREIRA, J. R. Processo de educação continuada de professores de educação física em contexto educacional inclusivo. Rev. Bras. Educ. Fís. Esp., São Paulo, v. 19, n. 2, p. 163-180, abr./jun. 2005.

DELGADO, E. I. Pilares do Interacionismo. São Paulo: Érica, 2003.

FARNHAM-DIGGORY, S. Paradigms of knowledge and instruction. Review of Educational Research, v. 64, n. 3, p. 463-477, jul./set. 1994.

FREIRE, Paulo. Pedagogia da indignação: cartas pedagógicas e outros escritos. São Paulo: Cortez, 2000. GILL, R. Análise de Discurso. In: BAUER, M. W.; GASKEL, G. (Ed.), Pesquisa Qualitativa com texto, imagem e som - Um Manual Prático, p. 244-270, 2002.

GOMES, N. L. Trajetórias escolares, corpo negro e cabelo crespo: reprodução de estereótipos ou ressignificação cultural? Rev. Bras. Educ., Rio de Janeiro, n. 21, set./dez. 2002.

GÜNTHER, M. C. C.; NETO, V. M. Formação permanente de professores de educação física na rede municipal de ensino de Porto Alegre: uma abordagem etnográfica. Rev. Paul. Educ. Fís., São Paulo, v. 14, n. 1, p. 72-84, jan./jun. 2000.

LAKATOS, E. M.; MARCONI, M. A. Metodologia Cientifica. São Paulo: Atlas, 1983.

MATUI, J. Construtivismo. São Paulo: Moderna, 2005.

MATURANA, H. Emocões e linguagem na educação e na política. Belo Horizonte: Ed. UFMG, 2002.

MONTEIRO, Maria Inês; CHILLIDA, Manuela de Santana Pi; BARGAS, Eliete Boaventura. Educação continuada em um serviço terceirizado de limpeza de um hospital universitário. Rev. Latino-Am. Enfermagem, Ribeirão Preto, v. 12, n. 3, mai./jun. 2004.

MOURA, E. R. F.; Francisco Holanda Jr.; RODRIGUES, M. S. P. Avaliação da assistência prénatal oferecida em uma microrregião de saúde do Ceará, Brasil. Cad. Saúde Pública, Rio de Janeiro, v. 19, n. 6, nov./dez. 2003.

NORMAN, P.; PARKER, S. The interpretation of change in verbal reports: Implications for health psychology. Psychology \& Health, v. 11, n. 2, p. 301-314, February, 1996.

OLIVIERA, M. L.; BASTOS, A. C. S. Práticas de atenção à saúde no contexto familiar: um estudo comparativo de casos. Psicol. Reflex. Crit., v. 13, n. 1. Porto Alegre, 2000.

PEIXOTO, M. A. P.; BRANDÃO, M. A. G.; SANTOS, G. dos: Metacognição como Tecnologia Educacional Simbólica, Rev. Bras. Ed Médica, v. 31, n. 1, p. 67-80, 2007.

PENNA, A.G. Introdução à aprendizagem e memória. Rio de Janeiro: Imago, 2001.

PEREIRA, F. R. P. Jovens em conflito com a lei: a violência na vida cotidiana. 2002, 220p. Dissertação (Mestrado em Psicologia). Faculdade de Filosofia, Ciências e Letras, Universidade de São Paulo, Ribeirão Preto, 2000. 
PERRENOUD, P. Pedagogia na escola das diferenças. Porto Alegre: Artmed, 2001. POZO, J.I. Teorias cognitivas da aprendizagem. Porto Alegre: Artmed, 2002.

RAKOWSKI, W. et al. Daily symptoms and behavioral responses. Medical Care, v. 26, n. 3, mar. 1988.

RESTA, D. G.; BUDÓ, M. L. D. A cultura e as formas de cuidar em família na visão de pacientes e cuidadores domiciliares. Acta Scientiarum. Health Sciences, Maringá, v. 26, n. 1, p. 53-60, 2004.

RIBEIRO, V.; MUNARI, D. B. Saúde mental em clientes cirúrgicos: o desenvolvimento de ações de enfermagem por meio do grupo de suporte/apoio. Rev. Bras. Enferm., v. 51, n. 1, p. 147-164, jan./mar. 1998.

RICHARDSON, A. The health diary: an examination of its use as a data collection method. Journal of Advanced Nursing, v. 19, n. 4, p. 782-791, 1994.

ROBERT, J.; STERNBER, G. Psicologia cognitiva. Porto Alegre: Artmed, 2000.

RUÉ, J. O que ensinar e por quê. São Paulo: Moderna, 2003.

SALOMON, D. V. Como fazer uma monografia. 2.ed. São Paulo: Martins Fontes, 1993.

SILVA, J. L. A., LOPES, M. J. M. Educação em saúde a portadores de úlcera varicosa por meio de atividades de grupo. Rev. Gaúcha Enferm., Porto Alegre, v. 27, n. 2, p. 240-250. jun. 2006.

SORIANO, J. B.; WINTERSTEIN, P. J. A constituição da intervenção profissional em educação física: interações entre o conhecimento "formalizado" e as estratégias de ação. Rev. Bras. Educ. Fís. Esp., São Paulo, v. 18, n. 4, p. 315-332, out./dez. 2004.

STOLLER, E. P. Interpretations of Symptoms by Older People. Journal of Aging and Health, v. 5, n. 1 , p. 58-81, 1993.

STOLLER, E. P.; FORSTER, L. E.; PORTUGAL, S. Self-care responses to symptoms by older people. Medical Care, v. 31, n. 1, 1993.

STRUCHINER, M.; GIANNELLA, T. R. Educação à distância: reflexões para a prática nas universidades brasileiras. Brasília: [s.n.], 2001.

TRONCHIN, D. M. R.; TSUNECHIRO, M. A. Cuidar e o conviver com o filho prematuro: a experiência do pai. Rev. Latino-Am. Enfermagem, Ribeirão Preto, v. 14, n. 1. jan./fev. 2006.

TRONCHIN, D. M. R. et al. O olhar dos usuários de um hospital de ensino: uma análise da qualidade assistencial às gestantes e aos recém-nascidos. Revista Texto \& Contexto Enfermagem, Florianópolis, v. 15, n. 3, ago. 2006.

WILLIS, G. B.; BERCINI, P. R. D. The use of verbal report methods in the development and testing of survey questionnaires. Applied Cognitive Psychology; v. 5, n. 3, p. 251-267. fev. 2006.

ZABALZA, M.A. Diários de aula. Portugal: Porto Ed., 1994.

ZAGO, M. M. F. Plano de ensino para o preparo da alta médica do paciente laringectomizado. 1990. 145p. Dissertação (Mestrado). Escola de Enfermagem de Ribeirão Preto, Universidade de São Paulo, Ribeirão Preto, 1990. 